\title{
Estudo longitudinal da aquisição fonológica de criança com Síndrome de Down
}

\author{
Jóice de Oliveira Ferreira* \\ Raquel Márcia Fontes Martins ${ }^{* *}$
}

Resumo: Este trabalho analisa a aquisição da fala de criança com Síndrome de Down em um estudo longitudinal, a fim de acompanhar características individuais de desenvolvimento. A pesquisa considera estratégias de reparo na aquisição e tem como suporte Modelos Baseados no Uso (BYBEE, 2001, 2010). Trata-se de um estudo de caso com uma criança, envolvendo gravações periódicas desde os seus 5 meses até os seus 2 anos de idade. A análise apontou uma aquisição sonora gradual, com a atuação de efeitos de frequência e produção preferencial de sons consonantais mais anteriores, além do tipo silábico formado pela estrutura consoante-vogal.

Palavras-chave: Aquisição fonológica. Síndrome de Down. Estudo Longitudinal.

\begin{abstract}
This paper analyzes the acquisition of speech of children with Down's syndrome in a longitudinal study in order to follow individual developmental characteristics. The research considers repair strategies in the acquisition and is supported by Models Based on the Use (BYBEE, 2001, 2010). It is a case study with a child, involving periodic recordings from his 5 months to his 2 years old. The analysis pointed to a gradual sound acquisition, with the effect of frequency effects, on the preferential production of earlier consonant sounds and the consonantvowel syllabic type.
\end{abstract}

Keywords: Phonological acquisition. Down's syndrome. Longitudinal study.

Résumé: Cet article analyse l'acquisition de la parole d'un enfant que atteints du syndrome de Down dans le cadre d'une étude longitudinale visant à suivre les caractéristiques de développement individuelles. La recherche prend en compte les stratégies de réparation dans l'acquisition et est soutenue par Modèles basés sur l'utilisation (BYBEE, 2001, 2010). C'est une étude de cas avec un enfant, comprenant des enregistrements périodiques de ses 5 mois à ses 2 ans. L'analyse a montrè une acquisition sonore progressive, avec l'effet des effets de fréquence, sur la production préférentielle de sons de consonance antérieurs et du type syllabique consonne- voyelle.

Mots-clés: Acquisition phonologique. Syndrome de Down. Étude longitudinale.

\footnotetext{
* Mestranda no Programa de Pós-Graduação de Letras do Departamento de Estudos da Linguagem da Universidade Federal de Lavras. http://orcid.org/00oo-0002-4473-6445.

** Professora das áreas de Linguística e Língua Portuguesa, do curso de letras do Departamento de Estudos da Linguagem da Universidade Federal de Lavras. http://orcid.org/oooo-0003-0321-3848
}

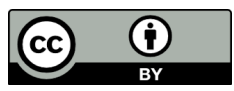




\section{Introdução}

A área de aquisição da linguagem apresenta grande debate, com diferentes visões sobre como uma criança adquire sua língua materna, no chamado período crítico de aquisição da linguagem, até os 5 anos de idade (TRASK, 2004). Em linhas gerais, o debate gira em torno de propostas de base empirista (SKINNER, 1957; PIAGET, 1979; VYGOTSKY, 1984) e de propostas de base inatista (CHOMSKY, 1959).

Seja em uma proposta ou outra, a maioria dos estudos se volta mais para a aquisição da fala típica, também denominada aquisição padrão, normal ou sem desvios (LAMPRECHT et al., 2004). Estudos em aquisição atípica ou com desvios são um desafio para os pesquisadores devido à complexidade de casos que este tipo de aquisição abarca (KAIL, 2013).

Em um recorte desta área, o presente estudo analisa a aquisição da fala de uma criança com Síndrome de Down em um estudo longitudinal, a fim de acompanhar características individuais de seu desenvolvimento (SLOBIN, 2015; FONTES MARTINS, 2007; OLIVEIRA-GUIMARÃES, 2008). A pesquisa considera estratégias de reparo ou fenômenos fonológicos realizados na aquisição (LAMPRECHT et al., 2004; LOUSADA, ALVES e FREITAS, 2017) e tem como suporte teórico Modelos Baseados no Uso (BYBEE, 2001). Especificamente, analisa-se a aquisição fonológica, observando a cronologia de aquisição dos fonemas e de padrões silábicos apresentada pela criança participante da pesquisa no período analisado.

Slobin (2015), ao realizar um estudo sobre pesquisas com línguas sinalizadas que se utilizam de teorias de línguas orais, faz uma advertência sobre o risco que é estudar a aquisição de fala atípica, usando uma teoria de aquisição de fala típica. Assim, é importante ressaltar que, baseado nessa proposta de Slobin (2015), o foco desta pesquisa é investigar a aquisição fonológica de criança com Síndrome de Down, atentando para as particularidades desse tipo de fala atípica. Oliveira-Guimarães (2008), estudando a aquisição de oclusivas alveolares, também tendo como suporte Modelos Baseados no Uso (BYBEE, 2001, 2010), aponta para a importância de se considerar o indivíduo no processo de aquisição, o que é a proposta deste estudo. 
Vale destacar que o interesse por este estudo surgiu, principalmente, a partir do nascimento da sobrinha de uma das pesquisadoras, a qual foi diagnosticada com Síndrome de Down¹. Para desenvolver este trabalho, foi realizado um estudo de caso com uma criança, uma menina, desde os seus 5 meses até os seus 2 anos de idade, o que totaliza 1 ano e 7 meses de pesquisa. Tratou-se, portanto, de um estudo longitudinal, envolvendo gravações periódicas durante esse tempo de coleta de dados. Além das gravações, o estudo contou com um diário de anotações do desenvolvimento da criança. Destaca-se que o estudo longitudinal permite que se avalie o desenvolvimento individual, observando-se, por exemplo, regressões no processo (LAMPRETCH et al., 2004; OLIVEIRA-GUIMARÃES, 2008). Isso será também observado neste estudo.

A seguir, é apresentada a fundamentação teórica deste trabalho, com uma descrição sobre a aquisição atípica da fala, as estratégias de reparo utilizadas pelas crianças durante a fase de aquisição, uma breve explanação sobre a Síndrome de Down e o uso da Placa Palatina de Castillo-Morales. Na sequência, é abordada a metodologia utilizada na pesquisa, seguida da análise aqui desenvolvida e das considerações finais deste estudo.

\section{Modelos Baseados no Uso em Aquisição}

Esta pesquisa se fundamenta em Modelos Baseados no Uso (BYBEE, 2001, 2010; PIERREHUMBERT, 2001, 2003). Os Modelos Baseados no Uso defendem que a língua emerge do uso e da experiência do falante. Esses modelos, de base empirista, postulam que a criança tem o adulto como alvo e adquire a língua em situações reais de interação, de modo que a gramática e o léxico emergem da experiência. Assim, tais modelos discordam da hipótese inatista no tocante à Gramática Universal (CHOMSKY, 1959) e são consensuais ao defenderem que o ser humano possui uma capacidade para a linguagem.

\footnotetext{
${ }^{1}$ Cariótipo da criança: 47,??,+21. Observação do laboratório: em todas as células analisadas, foi visualizada a trissomia livre do cromossomo 21. ?? pode ser XY (masculino) ou XX (feminino).
} 
Segundo Bybee (2001), o desenvolvimento da linguagem pode ser comparado com o ato de aprender a tocar piano, pois

\begin{abstract}
quando uma pessoa aprende a tocar piano, ele ou ela aprende não apenas a tocar as notas, mas a tocar as notas em sequência. Cada música tem sua própria sequência de notas que deve ser aprendida. A prática é essencial, os padrões motores que levam a execução fluente de sequências cada vez mais longas de notas devem ser automatizados para uma peça para que soe como música. Com prática, as transições entre as notas se tornam mais fluentes, e a velocidade de execução aumenta automaticamente. A fim de manter o ritmo e o tempo corretos, o executor deve, às vezes, conter-se e não tocar cada nota tão rápido quanto possível (BYBEE, 2001, p. 14. Tradução nossa). ${ }^{2}$
\end{abstract}

No mesmo viés de Bybee, Ferrari (2011, p. 149) considera que, "quando usamos símbolos para a comunicação intersubjetiva, encadeando-os em sequências, padrões de uso emergem e se tornam consolidados como construções gramaticais", dando origem à criatividade do falante diante do evento de uso vigente.

Ao contrário do que defendiam os gerativistas a respeito da existência de habilidades específicas da linguagem, os Modelos Baseados no Uso defendem que é importante identificar habilidades que estão relacionadas a outros domínios cognitivos e sociais como a identificação de padrões e a leitura de intenções (FERRARI, 2011; BYBEE, 2001; PIERREHUMBERT, 2003).

Na identificação de padrões, crianças na fase pré-silábica, ou seja, abaixo de um ano de idade, "buscam encontrar padrões repetidos naquilo que ouvem para construir unidades linguísticas" (FERRARI, 2011, p. 151). A identificação de padrões abarca habilidades como engatinhar, andar, reconhecer e identificar elementos em sequência e a habilidade de fazer analogias que são importantes para que a criança possa identificar como os adultos usam os símbolos linguísticos nos diversos eventos do cotidiano.

\footnotetext{
2 "When a person learns to play the piano, he or she learns not just to strike notes, but to strike notes in sequence. Each piece of music has its own sequence of notes that must be learned. Practice is essential; the motor patterns that lead to the fluent, striking of longer and longer sequences of notes must be automated for a piece to begin to sound like music. With practice, the transitions between the notes become more fluent, and the speed of execution automatically increases. In order to maintain the correct rhythm and tempo, the player must at times hold back and not play every note as fast as possible." (BYBEE, 2001, p. 14)
} 
Na leitura de intenções, a criança desenvolve habilidades como: chamar a atenção dos outros através de gestos não linguísticos; compreender as intenções comunicativas do adulto ou de seus pares; e utilizar os símbolos linguísticos de forma adequada, inicialmente com base na imitação e por meio de inversão de papéis.

Os Modelos Baseados no Uso também atribuem grande importância à questão da frequência (frequência de ocorrência e frequência de tipo) no processo de aquisição da linguagem da criança (BYBEE, 2001). Palavras de alta frequência ou de maior frequência de ocorrência têm maior probabilidade de fazer parte do léxico da criança, apresentando representação mental mais robusta. Já quanto à frequência de tipo - que se refere à frequência de um padrão linguístico -, nota-se que também um tipo mais frequente, como a sílaba CV (consoante-vogal) apresenta representação mental mais forte, o que pode influenciar na aquisição da linguagem pela criança, inclusive, nas estratégias de reparo ou fenômenos fonológicos que ela irá apresentar no seu desenvolvimento (BYBEE, 2001).

O indivíduo também é considerado nesses modelos que postulam que a gramática e o léxico, por emergirem do uso da língua, da experiência, são plásticos, dinâmicos e individuais (BYBEE, 2001, 2010; FONTES MARTINS, 2007; OLIVEIRAGUIMARÃES, 2008). Esse ponto teórico também será aqui considerado.

Passemos à próxima seção que caracteriza a aquisição atípica e trata das estratégias de reparo, utilizadas pelas crianças na aquisição do sistema fonológico.

\subsection{Aquisição fonológica atípica e estratégias de reparo}

Este estudo focaliza a aquisição da fala de criança com Síndrome de Down, um caso de aquisição atípica. Para tratar essa aquisição, é importante definir a sua “contraparte”, a aquisição típica. Segundo Lamprecht et al. (2004), a aquisição típica é aquela em que o desenvolvimento fonológico da língua alvo é alcançado de forma espontânea de acordo com a maioria das crianças de uma determinada faixa etária. Já a aquisição atípica seria aquela em que a criança não apresenta domínio do sistema 
fonológico da língua alvo em acordo com a maioria das crianças de uma mesma faixa etária.

$\mathrm{Na}$ aquisição atípica, a criança se apresenta em descompasso com o desenvolvimento da linguagem esperado nos níveis fonológico, sintático, semântico, morfológico e pragmático (MOTA, 2001). As definições para esses descompassos recebem diferentes nomenclaturas, como aquisição atípica, com desvio, não padrão. Há nomenclaturas que são menos usuais hoje, como fala anormal e fala errada (LAMPRECHT et al., 2004).

Mesmo que o desenvolvimento fonológico da criança apresente desvios, sua fala é sistemática, ou seja, não se pode considerar tais desvios como formas erradas que acontecem aleatoriamente. Portanto, "desvio não significa um sistema sem ordem, mas simplesmente um sistema cujos padrões não são idênticos à norma" (YAVAS, HERNANDORENA e LAMPRECHT, 2001, p. 10). Por mais que seja ininteligível ao observador, a fala com desvios não acontece de forma acidental, pois "possui um sistema consistente, um sistema de regras" (LAMPRECHT et al., 2004, p. 197), e as estratégias de reparo utilizadas pelas crianças seriam uma prova disso.

Durante o processo de aquisição da linguagem, as crianças traçam estratégias de reparo para se adequarem à língua-alvo (LOUSADA, ALVES e FREITAS, 2017). É preciso levar em consideração que tanto crianças que apresentam desvios fonológicos quanto crianças de desenvolvimento de fala típica apresentam semelhanças quanto às estratégias de reparo, o que ocorre "quando a criança enfrenta uma incapacidade em produzir determinado segmento ou estrutura silábica" (LAMPRECHT et al., 2004, p. 201), que ela ainda não aprendeu ou que ainda não é de seu domínio. Para exemplificar algumas estratégias de reparo, abaixo estão citados alguns exemplos retirados de Lamprecht et al. (2004):

No nível segmental:

- $\quad$ a dessonorização de obstruintes (ex.: 'abre' $\rightarrow$ ['api])

- $\quad$ a anteriorização (ex.: 'queijo' $\rightarrow$ ['kezu])

- $\quad$ a posteriorização (ex.: 'bolsa' $\rightarrow$ ['boja])

- $\quad$ a semivocalização de líquidas (ex.: 'cenoura' $\rightarrow$ ['noja]), 'colo' $\rightarrow$ ['kowu], 'folha' $\rightarrow$ ['foja])

- $\quad$ a substituição de líquida, geralmente de não lateral por lateral (ex.: 'passarinho' $\rightarrow$ [pasa'linu], 'barraca' $\rightarrow$ [ba'laka] 
- a não realização do segmento em onset simples (ex.: 'sabonete' $\rightarrow$

['eti], 'rua' $\rightarrow$ ['ua])

No nível silábico:

- a não realização do segundo membro de um onset complexo (ou redução de encontro consonantal) ( ex.: 'braço' $\rightarrow$ ['basu])

- a não realização da coda (ex.: 'carninha' $\rightarrow$ [ka'nija])

- a metátese (ex.: 'verde' $\rightarrow$ ['vredzi], 'dragão' $\rightarrow$ [da'grãw])

- a epêntese (ex.: 'brabo' $\rightarrow$ [ba'rabu])

- a não realização de uma ou mais sílabas (ex.: 'dormindo' $\rightarrow$ ['mindu], 'dinossauro' $\rightarrow$ ['sawo]).

Essas são apenas algumas estratégias de reparo adotadas pelas crianças durante a aquisição da linguagem, as quais focalizamos aqui. Na próxima seção, serão apresentadas algumas características da criança com Síndrome de Down e como acontece o seu desenvolvimento linguístico.

\subsection{Sobre a Síndrome de Down}

De acordo com Santana (2015), o médico pediatra inglês, John Langdon Down, descreveu, em 1866, a Síndrome de Down (SD) como uma patologia congênita que acarreta um atraso no desenvolvimento físico e mental da criança. A Síndrome de Down ou Trissomia do Cromossomo 21 é uma alteração cromossômica em que há um cromossomo a mais no par 21. As células de indivíduos típicos apresentam 23 pares de cromossomos, resultando em 46 cromossomos.

Em crianças com a Trissomia, o número total é de 47 cromossomos, ou seja, elas possuem três cópias do cromossomo 21 em todas as células do corpo. Nesse caso, podese dizer que acontece a não disjunção pré-zigótica do cromossomo 21 do pai ou da mãe. Já a trissomia em mosaico ou mosaicismo ocorre por disjunção pós-zigótica, apresentando células com 47 cromossomos e outras células com 46 cromossomos. Na translocação cromossômica, a trissomia não se dá de forma completa, apresentando um excesso de material no cromossomo 21 que se conecta a outros dois cromossomos, geralmente o 14 ou o 15, somando 46 cromossomos (LAVRA-PINTO, 2014). 
De acordo com Santana (2015), o professor Jérôme Lejeune descobriu, em 1959, que a anomalia cromossômica é responsável por alterações e malformação em vários órgãos, atingindo o cérebro e acarretando o atraso intelectual. As alterações entre os indivíduos podem variar devido às particularidades de cada um, acarretando diferentes graus de deficiência intelectual (leve, moderado ou severo).

Ainda segundo Santana (2015), os indivíduos com Síndrome de Down podem apresentar as seguintes características e malformações: boca pequena, palato mais estreito, protrusão lingual, ausência de selamento labial, sialorreia, hipotonicidade (tônus muscular diminuído), o que pode prejudicar o desenvolvimento dos movimentos como rolar, engatinhar, sentar, levantar, andar, entre outros. A criança com SD ainda pode apresentar algumas complicações de saúde como "malformação cardíaca; deficiência imunológica; problemas respiratórios; problemas de visão e de audição; problemas odontológicos" (SANTANA, 2015, p. 25).

Aspectos físicos e cognitivos, provenientes da condição de crianças com SD, podem comprometer a aquisição da linguagem. Além da hipotonicidade que afeta a área extra e intraoral, a criança pode apresentar também infecções de ouvido que podem causar perda auditiva. Somando-se esses aspectos ao comprometimento cognitivo, pode-se afirmar que a aquisição da linguagem em criança com Síndrome de Down é uma das áreas de desenvolvimento infantil mais afetadas (SCHWARTZMAN, 2003).

O diagnóstico e a intervenção precoces - com equipe multi ou interdisciplinar formada por otorrinolaringologista, fonoaudiólogo, pediatra, fisioterapeuta, entre outros profissionais - são de extrema importância para o desenvolvimento da criança com SD, respeitando-se as particularidades de cada sujeito. A família e a escola também possuem um papel indispensável ao propiciar à criança um ambiente acolhedor e estímulos desde os primeiros dias de vida, a fim de promover o seu desenvolvimento cognitivo e social (SANTANA, 2015). A respeito do desenvolvimento da linguagem da criança com SD, Schwartzman (2003) afirma que

[...] saber lidar com as interferências físicas e cognitivas que podem estar presentes nas crianças com SD significa minimizar o impacto que estas interferências podem criar sobre a leitura que o Outro faz da criança e sobre a aquisição de sua linguagem (SCHWARTZMAN, 2003, p. 206). 
Um recurso terapêutico que pode ser indicado para crianças com SD é a utilização da Placa Palatina de Castillo-Morales. Trata-se de um aparelho que foi desenvolvido pelo médico Rodolfo Castillo-Morales, o qual pode ser visto na Figura 1 a seguir.

Figura 1 - Placa Palatina de Castilho-Morales com botão estimulador

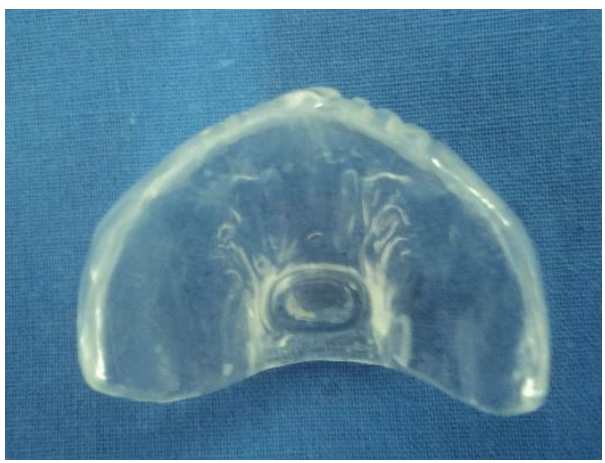

Fonte: Santana (2015, p. 27)

O uso dessa placa é indicado para crianças que apresentam hipotonia oromuscular, protrusão lingual e falta de selamento labial. A melhora na postura das estruturas orofaciais pode levar a um melhor desempenho nas funções orofaciais, como a sucção, a deglutição, a respiração (OVIEDO, 1999) e a fala, trazendo benefícios à qualidade de vida das crianças com SD.

O uso da placa geralmente é de fácil aceitação pela criança e, segundo Schwartzman (2003), o tratamento deve ser iniciado logo nos primeiros meses de vida com interrupção quando a criança consegue manter o selamento labial e a língua dentro da cavidade oral, estabelecendo-se a respiração nasal.

A placa, de custo acessível, é confeccionada com material acrílico e moldada individualmente. Ela possui um cilindro côncavo (botão) que deve ser ajustado no palato duro e possui também algumas ranhuras na área alvéolo-labial desse dispositivo. $\mathrm{O}$ objetivo é que a criança busque esse botão com a língua, reposicionando-a, de modo a conseguir manter o selamento dos lábios. O uso desse dispositivo deve ser feito na presença dos pais ou responsável, a fim de observar as reações da criança (SANTANA, 
2015). A indicação do dispositivo deve sempre ocorrer dentro de um programa de tratamento do complexo orofacial (CASTILLO-MORALES, 1999).

A seção a seguir trata da metodologia adotada nesta pesquisa, de caráter longitudinal.

\section{Metodologia}

Esta pesquisa analisa a aquisição da fala de uma criança com Síndrome de Down em um estudo de caso. Esse tipo de estudo "visa conhecer em profundidade o como e o porquê de uma determinada situação que se supõe ser única em muitos aspectos, procurando descobrir o que há nela de mais essencial e característico." (FONSECA, 2002. p. 33).

Vale destacar que esta pesquisa é realizada em uma proposta longitudinal, em que são realizadas várias coletas de dados com um mesmo informante em diferentes momentos (FONTES MARTINS, 2007; OLIVEIRA-GUIMARÃES, 2008). Esse tipo de

pesquisa permite observarem-se individualidades e particularidades no desenvolvimento da fala da criança, como os momentos de regressão, em que a criança deixa de produzir determinados segmentos ou estruturas sonoras que já produzia por um tempo, ou seja, regride na aquisição, mas depois avança novamente em seu desenvolvimento (LAMPRECHT et al., 2004; OLIVEIRA-GUIMARÃES, 2008).

Trata-se de um estudo de caso com uma menina, Mariana (nome fictício), cujos dados foram coletados no período de 5 meses a 2 anos de idade, o que soma 1 ano e 7 meses de pesquisa (entre 2016 e 2018). Destaca-se que esta criança é natural da cidade de Lavras (MG). Seus pais também são de Lavras (MG). A escolha da criança se deu por esta ser sobrinha de uma das pesquisadoras. Isso auxiliou na coleta de dados longitudinal, tendo em vista que se trata do estudo que acompanha o desenvolvimento da linguagem de uma criança ao longo do tempo, o que tende a ser facilitado quando o pesquisador tem familiaridade com a criança (SCARPA, 2012). 
Além disso, trata-se de uma pesquisa qualitativa. De acordo com Gehardt e Silveira (2009, p. 31), esse tipo de pesquisa "não se preocupa com representatividade numérica, mas, sim, com o aprofundamento de compreensão de um grupo social, de uma organização, etc”.

Ao longo da pesquisa foram feitas, sempre que possível, gravações de vídeo mensais (ou até mais de uma gravação por mês), utilizando-se um celular ${ }^{3} \mathrm{com}$ a única criança participante, Mariana, portadora de Síndrome de Down, a partir de seus 5 meses de idade. Mariana, sempre se mostrou uma criança muito esperta e atenta. As pessoas envolvidas nas coletas deste trabalho foram, além da pesquisadora, na maioria das vezes, a mãe e o pai da criança, mas também os avós maternos e o primo ( 5 anos mais velho que Mariana).

As gravações ocorriam ora na casa dos avós, onde mora a pesquisadora, ora na casa da criança e seus pais, onde havia sempre uma preocupação em deixar Mariana o mais a vontade possível, sempre respeitando o seu ritmo. $\mathrm{O}$ ambiente familiar foi muito importante para o desenvolvimento físico, emocional, intelectual e linguístico de Mariana.

A pesquisa sobre a aquisição de fala envolvendo criança não é uma tarefa fácil, pois o que se deseja é uma coleta de dados da fala espontânea em que esta coleta “caracteriza-se por não guiar a fala da criança de modo a fazê-la produzir determinadas construções específicas" (GROLA; SILVA, 2014, p. 94), mas nem sempre isso é possível, por isso foram utilizados recursos como brinquedos e estímulos visuais e sonoros (ver Quadro 1 à frente) para estimular a produção de fala e auxiliar na coleta. Os recursos utilizados ao longo da pesquisa foram: brinquedo de pano, brinquedos musicais, vídeos, bonecos, jogos didáticos, brinquedos feitos em casa como chocalhos, entre outros.

De acordo com o crescimento da criança participante da pesquisa, foram incorporados outros brinquedos, livros, revistas, alimentos e até mesmo a presença de animais como cachorro e pintinhos que ficavam na casa dos avós e cavalo em passeios ao sítio da família. De acordo com Oliveira-Guimarães (2008, p. 105), “a utilização de objetos e brinquedos, com os quais a criança possa interagir efetivamente, embora possa

\footnotetext{
3 Informações técnicas do aparelho celular: Sansung Galaxy Gran 2 Duos TV.
} 
influenciar a produção lexical, parece ser um meio eficiente, pois contribui para tornar mais amigável a aproximação inicial entre a criança e a pesquisadora, propiciando um ambiente lúdico".

Ressalta-se que a criança participante desta pesquisa começou a usar a placa palatina de Castillo-Morales com apenas 1 ano de idade, porque os pais dela não encontraram profissionais que trabalhassem com a placa na cidade onde moram (Lavras - MG), tendo de procurar auxílio em outra cidade maior, com mais recursos (Belo Horizonte - MG). O tratamento foi até 1 ano e 4 meses de idade da criança, apresentando resultados satisfatórios. Destaca-se que a criança envolvida na pesquisa recebe tratamento fonoaudiológico desde os 5 meses de vida.

Por ser um bebê, nem sempre as gravações aconteciam com sucesso, pois Mariana às vezes se mostrava pouco disposta a brincar e até mesmo para produzir sons. Quando isso acontecia, as gravações eram interrompidas, pois havia sempre uma preocupação com o bem estar da criança. As interrupções aconteciam também quando havia interferência de ruídos e até mesmo a falta de ferramentas tecnológicas. Cada seção de gravação durou, em média, 10 minutos. Com o passar do tempo, Mariana começou a perceber a presença da câmera, o que dificultou as gravações.

A partir de um ano, foi feito um diário para anotar as produções orais diárias de Mariana, bem como algumas habilidades diversas desenvolvidas por ela ao longo da pesquisa. Próximo dos 2 anos de idade, ela já conseguia pronunciar um número grande de palavras e com maior rapidez. No decorrer das coletas, ao todo 58 seções, os dados foram submetidos à análise auditiva para tratamento qualitativo e realização de transcrições fonéticas.

A seguir, o Quadro 1 apresenta os brinquedos e outros recursos utilizados na coleta de dados com Mariana, para estimular a produção de sua fala.

Quadro 1 - Brinquedos e outros recursos utilizados na pesquisa

\begin{tabular}{|c|c|c|c|c|c|}
\hline Brinquedos & Alimentos & $\begin{array}{c}\text { Revistas/Livros/C } \\
\text { Ds/ } \\
\text { Vídeos/Músicas }\end{array}$ & Animais & $\begin{array}{c}\text { Pessoas do } \\
\text { Convívio da } \\
\text { criança }\end{array}$ & Outros \\
\hline $\begin{array}{c}\text { Brinquedo de } \\
\text { pano }\end{array}$ & Água & $\begin{array}{c}\text { Neném, gato, onça } \\
\text { (figuras), }\end{array}$ & Cachorro & Jóice & Fralda \\
\hline
\end{tabular}




\begin{tabular}{|c|c|c|c|c|c|}
\hline $\begin{array}{c}\text { Chocalhos } \\
\text { (feitos em } \\
\text { casa) } \\
\text { Porco }\end{array}$ & Banana & Músicas infantis & Cavalo & Ivan & Óculos \\
\hline Barata & Danone & Vídeos educativos & Vaca & Lane & Mamadeira \\
\hline Colher & Biscoito & $\begin{array}{l}\text { Lara (coruja) - } \\
\text { desenho }\end{array}$ & Pintinhos & Felipe (primo) & $\begin{array}{c}\text { Prendedores } \\
\text { de roupa e } \\
\text { caixas de } \\
\text { papel }\end{array}$ \\
\hline Panelinha & Mamão & & & Meire & \\
\hline Colher & Bolacha & & & Avó & \\
\hline $\begin{array}{c}\text { Casinha } \\
\text { Educativa } \\
\text { (cores, letras, } \\
\text { números e } \\
\text { figuras } \\
\text { geométricas) }\end{array}$ & & & & Avô & \\
\hline $\begin{array}{c}\text { Controle } \\
\text { remoto } \\
\text { [cores, } \\
\text { número } \\
\text { (voz)] }\end{array}$ & & & & $\begin{array}{l}\quad \text { Colegas da } \\
\quad \text { Escola: } \\
\text { a) Enzo } \\
\text { b) Cecília } \\
\text { c) Bárbara } \\
\text { d) Bárbara } \\
\text { (Babi) } \\
\text { e) Fernando } \\
\text { f) Álvaro } \\
\text { g)Túlio } \\
\text { Professores/ } \\
\text { Monitores } \\
\text { h) Fernanda } \\
\text { i) Érica } \\
\text { j) Gabriela } \\
\text { (Gabi) }\end{array}$ & \\
\hline Carrinhos & & & & & \\
\hline
\end{tabular}

Fonte: Acervo da pesquisa

A seguir, são apresentadas a análise e os resultados da pesquisa realizada com a criança Mariana, no estudo longitudinal.

4 O estudo longitudinal da aquisição de fala de uma criança com Síndrome de

\section{Down}


Nesta seção, são apresentados os resultados e a análise dos dados da pesquisa sobre o desenvolvimento fonológico da criança com Síndrome de Down, Mariana. A série de quadros de análise apresentada, a partir deste momento, demonstrará: o número da seção de coleta; a idade da criança à época de cada coleta; o período (mês/ano) de gravação; a(s) produção(ões) de fala ${ }^{4}$ realizada(s) por Mariana em cada seção; e algumas observações a respeito das habilidades desenvolvidas pela criança que foram consideradas relevantes para a pesquisa. Veja-se, assim, o Quadro 2 a seguir:

Quadro 2 - Dados coletados: Faixa etária de 5 meses a 10 meses

\begin{tabular}{|c|c|c|c|c|}
\hline Seção & Idade & Período & $\begin{array}{l}\text { Produção de } \\
\text { fala }\end{array}$ & Observações \\
\hline 1 & 00:05;00 5 & Março/2016 & $\begin{array}{c}\text { BDA BDA } \\
\text { BDA } \\
\text { [bda] [bda] } \\
\text { [bda] }\end{array}$ & Balbucio \\
\hline 2 & oo:o6;00 & Junho/2016 & $\begin{array}{l}\text { DÃDÃDÃ } \\
\text { [dãdã'dã] }\end{array}$ & Balbucio \\
\hline 3 & oo:o8;00 & Agosto/2016 & $\begin{array}{l}\text { TADADATÁ } \\
\text { [tadada'ta] }\end{array}$ & Balbucio \\
\hline 4 & oo:09;00 & Setembro/2016 & $\begin{array}{c}\text { Sem } \\
\text { ocorrências }\end{array}$ & $\begin{array}{l}\text { Sem produção de fala } \\
\text { Neste mês, foi observado um atraso quanto à } \\
\text { fala. Acredita-se que tenha sido porque } \\
\text { Mariana estava aprendendo outras habilidades } \\
\text { como: } \\
\text { a) ficar sentada sozinha sem nenhum apoio; } \\
\text { b) ficar de pé se apoiando em alguma coisa; } \\
\text { c) ficar no chão sem engatinhar, mas já } \\
\text { começando a flexionar os joelhos. }\end{array}$ \\
\hline 5 & oo:10;00 & Outubro/2016 & $\begin{array}{c}\text { TATATÁ/ } \\
\text { TETETÉ } \\
\text { [tata'ta] } \\
\text { [tets't } \varepsilon]\end{array}$ & $\begin{array}{l}\text { - Balbucio; } \\
\text { - Mariana volta a apresentar produções } \\
\text { sonoras; } \\
\text { - Habilidades desenvolvidas: } \\
\text { a) mandar beijos; } \\
\text { b) APITAR - aprendeu a apitar } \\
\text { durante a terapia com a } \\
\text { fonoaudióloga para facilitar a } \\
\text { produção das bilabiais (ex.: mamá, } \\
\text { papá). }\end{array}$ \\
\hline
\end{tabular}

Fonte: Acervo da pesquisa

\footnotetext{
${ }^{4}$ Vale ressaltar que, para facilitar a leitura, a transcrição da produção da fala é ortográfica, quando é possível representá-la pela escrita alfabética. Em alguns casos, utiliza-se transcrição fonética.

${ }^{5}$ Em uma notação como, por exemplo, oo:05;oo, entender por ano: mês; dia. Nesse caso, 5 meses de idade.
} 
A criança participante apresentou balbucio dos 5 aos 10 meses com os segmentos [b], [t], [d] seguidos das vogais [a], [ã], [e] no padrão silábico $C V$, como pode ser observado no Quadro 2. Na coleta de 9 meses, não houve ocorrências, mas é possível perceber que a criança estava desenvolvendo outras habilidades nesse período, como ficar sentada sozinha sem apoio, ficar de pé apoiada em alguma coisa e flexionar os joelhos querendo engatinhar (LAMPRECHT et al., 2004; PIERRHUMBERT, 2003).

Observa-se, no Quadro 3, os dados coletados na faixa etária da criança participante, de 11 meses a 1:02 de idade.

Quadro 3- Dados coletados: faixa etária 11 meses a 1:02

\begin{tabular}{|c|c|c|c|c|}
\hline Seção & Idade & Período & $\begin{array}{l}\text { Produção de } \\
\text { fala }\end{array}$ & Observações \\
\hline 6 & oo:11;08 & Novembro/2016 & $\begin{array}{c}\text { Sem } \\
\text { ocorrências }\end{array}$ & Gravação do apito \\
\hline 7 & $00: 11 ; 26$ & Dezembro/2016 & $\begin{array}{c}\text { Sem } \\
\text { ocorrências }\end{array}$ & $\begin{array}{l}\text { Início do Uso da Placa Palatina de Castillo } \\
\text { Morales }\end{array}$ \\
\hline 8 & 1:00;09 & Dezembro/2016 & $\begin{array}{c}\text { Sem } \\
\text { ocorrências }\end{array}$ & $\begin{array}{c}\text { Diário } \\
\text { Habilidade: a) Brinca de esconde-esconde com } \\
\text { uma fralda; b) dança ao ouvir uma música; c) } \\
\text { Fica de pé dentro do berço. }\end{array}$ \\
\hline 9 & 1:02 & Fevereiro/2017 & $\begin{array}{c}\text { Sem } \\
\text { ocorrências }\end{array}$ & Habilidade: Começou a engatinhar \\
\hline 10 & 1:02;01 & Fevereiro/2017 & $\begin{array}{l}\text { ADA } \\
\text { ['a.də] }\end{array}$ & $\begin{array}{c}\text { Início das Primeiras Palavras - } \\
\text { ADA (água) }\end{array}$ \\
\hline 11 & 1:02;07 & Fevereiro/2017 & $\begin{array}{c}\text { Sem } \\
\text { ocorrências }\end{array}$ & $\begin{array}{l}\text { Entende os comandos como: "Cadê o } \\
\text { barrigão?" - Mariana bate as mãos na barriga. } \\
\text { "Cadê o pé?", "Cadê o pintinho amarelinho”. }\end{array}$ \\
\hline
\end{tabular}

Fonte: Acervo da pesquisa

Nesta faixa etária, entre 11 meses e 1:02, a criança ainda balbuciava, mas com menor frequência. Entre 11 meses e 1:02, Mariana não apresentou ocorrência de fala durante as coletas; seus interesses pareciam estar mais voltados para outras habilidades cognitivas como brincar de esconde-esconde com uma fralda, dançar ao ouvir uma música, ficar de pé dentro do berço e engatinhar. Aos 11;26, a criança começou a usar a Placa Palatina de Castillo-Morales para reposicionamento da postura lingual e selamento labial (permanência de boca fechada fora dos eventos de fala e mastigação).

Ao completar 1:02;01 de idade, a criança deu início à produção de sua primeira palavra $a d a \rightarrow[$ 'a.də] $\rightarrow$ água, em que se pode perceber a substituição do segmento /g/ por /d/, o que seria uma estratégia de reparo de anteriorização (LAMPRECHT et al., 
2004) com preservação do traço de sonoridade. A seguir, são apresentados os dados coletados da informante na faixa etária de 1:03 a 1:05 de idade.

Quadro 4 - Dados coletados: faixa etária 1:03 a 1:05

\begin{tabular}{|c|c|c|c|c|}
\hline Seção & Idade & Período & Produção de fala & Observações \\
\hline 12 & $1: 3$ & Março/2017 & $\begin{array}{l}\text { ANDÁ } \\
\text { [ə̃.'da] }\end{array}$ & (andar) (1 $1^{\mathrm{a}}$ vez) \\
\hline 13 & $1: 4 ; 10$ & Abril/2017 & ADA- ['a.də] & ADA (água) \\
\hline 14 & 1:04;02 & Abril/2017 & $\begin{array}{c}\text { ATATA- [a.'ta.tə] } \\
\text { NENÊ/ } \\
\text { NÊNÊNÊ } \\
\end{array}$ & $\begin{array}{l}\text { (batata e neném) } \\
1^{\underline{\underline{a}} \text { vez }}\end{array}$ \\
\hline 15 & 1:04;14 & Abril/2017 & Sem ocorrências & $\begin{array}{l}\text { Expressões faciais: careta, beijo, franzir testa } \\
\text { etc. }\end{array}$ \\
\hline 16 & 1:04;15 & Abril/2017 & Sem ocorrências & Encerrou o uso da PLACA PALATINA \\
\hline 17 & 1:04;20 & Abril/2017 & $\begin{array}{l}\text { NONONO } \\
\text { [nono'no] }\end{array}$ & NONONO (não) \\
\hline 18 & 1:04;22 & Abril/2017 & $\begin{array}{c}\text { ADA } \\
\text { ['a.də] } \\
\text { ATATA [a.'ta.tə] } \\
\text { NENÊ/ } \\
\text { NÊNÊNÊ } \\
\text { CADÊ }{ }^{6} \\
\text { [ka.'de] }\end{array}$ & $\begin{array}{c}\text { água, batata, neném, cadê } \\
\text { Habilidade: Apontar para figuras ex.: neném. }\end{array}$ \\
\hline 19 & 1:04;26 & Abril/2017 & $\begin{array}{c}\text { ADA } \\
\text { ATATA [a.'ta.tə] } \\
\text { BATATA [ba.'ta.tə] } \\
\text { NONONO }\end{array}$ & ada (água) e atata/batata (batata) \\
\hline 20 & 1:04;27 & Maio/2017 & AUDA ['aw.də] & Fralda \\
\hline 21 & $1: 04 ; 28$ & Maio/2017 & ATA ['a.tə:] & $\begin{array}{l}\text { Pegou um brinquedo (Dona Baratinha) e } \\
\text { falou ATA (barata) - } 1^{\mathrm{a}} \text { vez. }\end{array}$ \\
\hline 22 & 1:05;08 & Maio/2017 & $\begin{array}{l}\text { BANHANHA } \\
\text { ['ba. na.nə.] }\end{array}$ & $\begin{array}{l}\text { Na casa dos avó pegou uma banana e falou } \\
\text { [bañaña]. OBS.: Mariana, já está aprendendo } \\
\text { sobre as frutas com a fonoaudióloga através } \\
\text { da música "A Música das frutas". Mariana } \\
\text { quando ouve essa música, balança os } \\
\text { bracinhos no ritmo da música e reconhece a } \\
\text { palavra banana. }\end{array}$ \\
\hline 23 & 1:05;11 & Maio/2017 & $\begin{array}{l}\text { ATO ['a.tv] } \\
\text { MA }\end{array}$ & $\begin{array}{c}\text { Habilidade: Fica em pé e inicia marcha com } 3 \\
\text { passos. } \\
\text { ATO (gato) } \\
\text { MA (mãe) }\end{array}$ \\
\hline 24 & 1:05;14 & Maio/2017 & 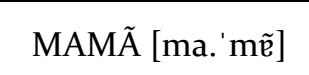 & MAMÃ (mamãe) - $1^{\underline{\underline{a}}}$ vez \\
\hline 25 & 1:05;15 & Maio/2017 & $\begin{array}{l}\text { IETA } \\
\text { ['ie.tə] }\end{array}$ & $1^{\mathrm{a}}$ vez (brinquedo de borracha-borboleta) \\
\hline
\end{tabular}

${ }^{6} \mathrm{~A}$ partir deste quadro, os segmentos marcados com realce cinza indicam dúvida quanto à produção sonora realizada pela criança participante da pesquisa. 


\begin{tabular}{|c|c|c|c|c|}
\hline 26 & $1: 05 ; 18$ & Maio/2017 & TÁTA ['ta.tə] & $\begin{array}{c}\text { Antes pronunciava ATA e agora TÁTA } \\
\text { (barata) }\end{array}$ \\
\hline 27 & $1: 05 ; 30$ & Junho/2017 & Sem ocorrências & $\begin{array}{c}\text { Habilidade: Segura a colher sozinha para } \\
\text { comer }\end{array}$ \\
\hline
\end{tabular}

Fonte: Acervo da pesquisa

Entre 1:3 a 1:5, Mariana apresentou um considerável incremento no seu inventário de sons, com a produção dos seguintes segmentos $[\mathrm{t}],[\mathrm{d}],[\mathrm{b}],[\mathrm{m}],[\mathrm{n}],[\mathrm{p}],[\mathrm{a}],[\mathrm{e}],[\mathrm{o}]$; com preferência pelos sons alveolares $[t],[d],[n]$ e pelas vogais [a], [ã], [e], [ẽ], [o]. A partir da seção 18 (1:4;22), começam a ocorrer pronúncias que se configuram como casos de dúvida na análise auditiva dos dados. Essas pronúncias podem indicar a gradualidade da aquisição da linguagem (BYBEE, 2001, 2010; PIERREHUMBERT, 2003), proposta por Modelos Baseados no Uso. Segundo Bybee (2001), a criança, em aquisição, desenvolve conhecimento da gradiência fonética, produzindo dados gradientes em que pode haver uma sobreposição de gestos articulatórios dos sons ou uma redução do gesto que leva a essa pronúncia que, na análise auditiva, torna-se duvidosa. Esse é um aspecto teórico que deve ser considerado como hipótese para a interpretação desses dados de Mariana.

É possível observar a aférese da consoante oclusiva bilabial vozeada /b/ em início de palavra, em que a criança mostrou maior facilidade em começar a palavra pela vogal central /a/ na posição de sílaba tônica, como pode ser observado também nas seguintes palavras: atata $\rightarrow$ [a.'ta.tə] $\rightarrow$ batata, ata $\rightarrow[$ a.tə:] $\rightarrow$ barata. Também se verifica a aférese da consoante oclusiva velar vozeada [g] em início de palavra: ato $\rightarrow$ ['a.tv] $\rightarrow$ gato.

Mariana começou a produzir o segmento /n/ em (banhanha $\rightarrow[$ 'bə. na.nə.] $\rightarrow$ banana); fez uso da estratégia de reparo da reduplicação da estrutura silábica canônica CV em não $\rightarrow$ [nonono], neném $\rightarrow$ [nenene], barata $\rightarrow$ táta $\rightarrow[$ 'ta.to, mamãe $\rightarrow$ mamã $\rightarrow[$ ma.m' $\tilde{e}] ;$ fez a estratégia de reparo da redução de encontros consonantais. Ex.: auda $\rightarrow[a w d a]$. Essa preferência pela produção da sílaba $\mathrm{CV}$, mais frequente na língua, também pode apontar para um efeito de frequência na aquisição da linguagem (BYBEE, 2001; OLIVEIRA-GUIMARÃES, 2008).

Houve uma dúvida quanto ao segmento produzido nas seguintes palavras: cadê $\rightarrow[$ Ka.'de], batata $\rightarrow$ [ba.'ta.tə], pois percebeu-se a emergência de um gesto articulatório consonantal, mas não foi possível identificar o segmento produzido de modo pleno. A criança participante parece ter produzido a vogal /i/ para substituir o 
segmento /l/ que ainda não consegue produzir em ieta $\rightarrow$ ['ie.tə] $\rightarrow$ borboleta, o que é também uma estratégia de reparo comum na aquisição, a vocalização das líquidas /1/ e /§/. No próximo quadro (Quadro 5), será apresentada a análise dos dados coletados da faixa etária de 1:06 a 1:09 de idade.

Quadro 5 - Dados coletados: faixa etária 1:06 a 1:09

\begin{tabular}{|c|c|c|c|c|}
\hline Seção & Idade & Período & Produção de fala & Observações \\
\hline 28 & 1:06;14 & Junho/2017 & $\begin{array}{l}\text { ACÓDA DJA } \\
\text { [a.'ko.də 'dzə] } \\
\end{array}$ & $\begin{array}{c}\text { Brincando com bonecos } \\
\text { Acorda dia } \\
\end{array}$ \\
\hline 29 & 1:06;15 & Junho/2017 & Ááá [a:] & Vogal “A” (ááá) \\
\hline 30 & 1:07;04 & Julho/2017 & ANA ['a.nə] & Banana \\
\hline 31 & 1:07;07 & Julho/2017 & $\begin{array}{l}\text { ANA, ANANA } \\
\text { ['a.na] [a.'na.nə] }\end{array}$ & Banana \\
\hline 32 & 1:07;11 & Julho/2017 & $\begin{array}{c}\text { ÓCE } \\
\text { [s] dentalizado } \\
\text { ['o.si] } \\
\text { OTO/TOTOTO } \\
\text { ['o.to] [to.'to.to] }\end{array}$ & $\begin{array}{l}\text { Jóice } \\
\text { Biscoito }\end{array}$ \\
\hline 33 & 1:07;1 & Julho/2017 & ANA ['a.nə] & Banana \\
\hline 34 & 1:07;18 & Julho/2017 & $\begin{array}{c}\text { USU } \\
{[\text { 'u.su] }}\end{array}$ & Urso \\
\hline 35 & $1: 07 ; 22$ & Julho/2017 & $\begin{array}{l}\text { OTA } \\
\text { OTO } \\
\text { ['o.to] }\end{array}$ & $\begin{array}{l}\text { Garota (nome de sua cachorra) } \\
\text { Quando passa pelo pote de biscoito, a } \\
\text { criança aponta e fala OTO (biscoito). }\end{array}$ \\
\hline 36 & 1:07;30 & Julho/2017 & $\begin{array}{l}\text { ANANA } \\
\text { [a.'na,nə] }\end{array}$ & Banana \\
\hline 37 & $1: 08$ & Agosto/2017 & $\begin{array}{c}\text { AZ } \\
\text { [az] } \\
\text { [z] dentalização } \\
\text { ACHA } \\
\left.\text { [a. } \int ə\right] \\
\end{array}$ & $\begin{array}{l}\text { Na fonoterapia falou "Az" - Azul. } \\
\text { Surgimento do [J]: Bolacha }\end{array}$ \\
\hline 38 & 1:08;00 & Agosto/2017 & Sem ocorrências & $\begin{array}{l}\text { 1) Já usa Simbolismos, ou seja, pega um objeto } \\
\text { e simula que é outro, por exemplo, um } \\
\text { controle-remoto torna-se um celular; pega } \\
\text { qualquer objeto e simula que é um neném e } \\
\text { começa a balançar e cantar para ele dormir. } \\
\text { 2) Separa objetos por classe (categorização): } \\
\text { fogão, panelinhas, colheres etc. }\end{array}$ \\
\hline 39 & 1:08;07 & Agosto/2017 & $\begin{array}{l}\text { ANA ANANA } \\
\text { ['a.nə] ou } \\
\text { [a.'nə.nə] }\end{array}$ & Banana \\
\hline 40 & 1:08;09 & Agosto/2017 & $\begin{array}{l}\text { ANA ANANA } \\
\text { ['a.nə] ou } \\
\text { [a.'nə.nə] }\end{array}$ & Rayana \\
\hline
\end{tabular}


FERREIRA, Jóice de Oliveira; LUCENA, MARTINS, Raquel Márcia Fontes

\begin{tabular}{|c|c|c|c|c|}
\hline 41 & 1:08;13 & Agosto/2017 & NONE ['no.ni] & Danone - none \\
\hline 42 & $1: 08 ; 13$ & Agosto/2017 & $\begin{array}{c}\text { ÔNS } \\
{[\text { 'õ.s }]-[\mathrm{s}]} \\
\text { dentalizado }\end{array}$ & Onça - ôns \\
\hline 43 & 1:08;16 & Agosto/2017 & $\begin{array}{l}\text { MUUU } \\
\text { [mu:] }\end{array}$ & $\begin{array}{c}20 / 08 / 17 \\
\text { Imita som da vaca }\end{array}$ \\
\hline 44 & 1:08;20 & Agosto/2017 & & $\begin{array}{c}\text { Início: “CADERNO DA MARIANA" } \\
\text { Contém figuras de lugares, objetos, animais } \\
\text { e fotos das pessoas do seu convívio. }\end{array}$ \\
\hline 45 & $1: 08 ; 21$ & Agosto/2017 & $\begin{array}{l}\text { APA OTA } \\
\text { ['a.pa'otə] }\end{array}$ & $\begin{array}{l}\text { Água, Garota (nome de sua cachorra) } \\
\text { INIÍCIO DE SENTENÇA DE DUAS } \\
\text { PALAVRAS } \\
\text { Durante a gravação apontou o dedo para a } \\
\text { água da cachorra e pronunciou "apa... Ota". }\end{array}$ \\
\hline 46 & $1: 08 ; 23$ & Agosto/2017 & $\begin{array}{c}\text { MAMÃ [ma.mõ] } \\
\text { MUUU } \\
\text { [mu:] } \\
\text { OTO } \\
\text { ['o.tu] } \\
\text { OTO } \\
\text { ['o.tu] }\end{array}$ & $\begin{array}{c}\text { Mamão - mamã } \\
\text { Muuu - (som da vaca) } \\
\text { Outro - (oto): aponta para outro carro, } \\
\text { outro cachorro etc. }\end{array}$ \\
\hline 47 & $1: 08 ; 25$ & Agosto/2017 & {$[\mathrm{h}]$} & Imita leão e ronco, utilizando o " $\mathrm{r}$ " glotal \\
\hline 48 & 1:09;05 & Setembro/2017 & $\begin{array}{c}\text { ADA, AZADA } \\
\text { ['a.də] [a.'zadə] }\end{array}$ & Pesada - ada, azada \\
\hline 49 & 1:09;06 & Setembro/2017 & $\begin{array}{l}\text { ANA, ANANA } \\
\text { ANA, ANANA } \\
\text { ['a.nə] ou } \\
\text { [a.'na.nə] }\end{array}$ & Banana, Rayana \\
\hline 50 & 1:09;06 & Setembro/2017 & $\begin{array}{l}\text { ÓCE ['o.si] } \\
\text { OTA } \\
\text { ['o.tə] } \\
\text { ATA ['a:.tə] } \\
\text { ÁGUA } \\
\text { ['a.pa] ou ['a.də] } \\
\text { MAMÃ [ma.'mə̃] } \\
\text { MUUU [mu:] } \\
\text { AAA [a:] } \\
\text { APA/APAPÁ } \\
\text { ['a.pa][a.pa.'pa] } \\
\text { APA/APAPÁ } \\
\text { ['a.pa][a.pa.'pa] }\end{array}$ & 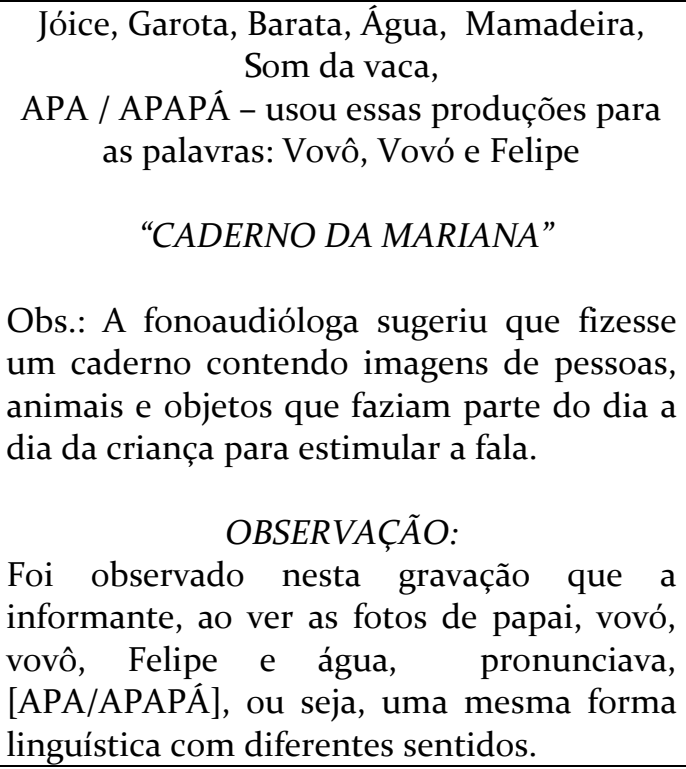 \\
\hline 51 & 1:09;11 & Setembro/2017 & $\begin{array}{l}\text { AMA ['a.mə] } \\
\text { AMA MAMÃ } \\
\text { ['a.məma.'ma] } \\
\text { AMAPAPÁ } \\
\text { ['a.məpa.'pa] }\end{array}$ & $\begin{array}{c}\text { AMA } \\
\text { SENTENÇAS DE DUAS PALAVRAS } \\
\text { AMA MAMÃE } \\
\text { AMA PAPAI } \\
\text { AMA JÓICE }\end{array}$ \\
\hline
\end{tabular}




\begin{tabular}{|c|c|c|c|c|}
\hline & & $\begin{array}{c}\text { AMA ÓCE } \\
\text { ['a.mə'o.si] }\end{array}$ & \\
\hline 52 & $1: 09 ; 24$ & Setembro/2017 & $\begin{array}{c}\text { ITO } \\
\text { ['i.to] }\end{array}$ & Pirulito \\
\hline
\end{tabular}

Fonte: Acervo da pesquisa

A criança participante, entre 1:6 a 1:9, apresentou apagamento da líquida não lateral em coda, ou seja, reduzia o padrão silábico $\mathrm{CVC}$ por $\mathrm{CV}$, estratégia de reparo comum na aquisição (LAMPRECHT et al., 2004): acóda $\rightarrow\left[a^{\prime} k \jmath d ə\right] \rightarrow a c o r d a$. Esse processo fonológico de apagamento de coda pode ocorrer também, com frequência, na adolescência e início da vida adulta (LAVRA-PINTO, 2014). Vale destacar, mais uma vez, que a sílaba CV é o tipo silábico mais frequente em português, o que poderia indicar uma estratégia que visa aproximar a produção de um padrão mais frequente (BYBEE, 2001), o que indica um efeito de frequência na aquisição. Outros destaques são: surgimento do segmento [dz] em $d_{3} a \rightarrow\left[d_{3} \partial\right] \rightarrow d i a ;$ prolongamento da vogal central /a:/; aférese da consoante oclusiva bilabial /b/ em início de palavra: ana $\rightarrow$ ['a.nə] $\rightarrow$ banana e anana $\rightarrow[a$.'na.nə] $\rightarrow$ banana; não realização de sílaba átona em início de palavra none $\rightarrow$ ['no.ni] $\rightarrow$ danone, aférese da oclusiva bilabial desvozeada /p/ em início de palavra ada, azada $\rightarrow[$ [a.də] [a.'zadə] $\rightarrow$ pesada, bem como a dentalização nos segmentos /s/ (fricativa alveolar desvozeada) e /z/ (consoante fricativa alveolar vozeada). Ocorre também a pronúncia a partir da sílaba tônica: itu $\rightarrow$ ['i.tv] $\rightarrow$ pirulito; oto $\rightarrow[$ 'o.t $] \rightarrow$ biscoito; oto $\rightarrow[$ 'o.tv $] \rightarrow$ outro, os dois últimos exemplos possuem a mesma estrutura linguística, mas com sentidos diferentes.

A criança participante começou a combinar palavras isoladas, dando início à sentença de duas palavras (GROLLA e SILVA, 2014; KAIL, 2013): apa... Ota $\rightarrow[$ 'a.pa 'otə] $\rightarrow$ água/Garota-nome da sua cachorra, com a idade de 1:08:21, o que está em paralelo com o desenvolvimento típico (GROLLA e SILVA, 2014). Reduz semivogal em mamã $\rightarrow[$ ma.mõ] $\rightarrow$ mamão; deixa de pronunciar ada $\rightarrow[$ 'a.də] $\rightarrow a ́ g u a$ e passa a pronunciar com maior frequência $a p a \rightarrow[$ 'a.pa]=água, ou seja, anterioriza mais ainda a pronúncia de $[\mathrm{g}]$ para $/ \mathrm{p} /$.

Mariana mostrou um grande número de estratégias de reparo, utilizando os segmentos /m/ e /p/ que são sons presentes em palavras do seu cotidiano, ou seja, que têm maior frequência de ocorrência, tais como papai e mamãe, o que também pode 
indicar efeitos de frequência na aquisição da fala (BYBEE, 2001, 2010). Nos exemplos, papai (apa/apapá), vovó (apa/apapá), vovô (apa/apapá), Felipe (apa/apapapá), é possível perceber que a informante apresenta preferência por segmentos/palavras que já são do seu conhecimento para fazer referência a diferentes significantes, ou seja, usa a mesma forma linguística com diferentes significados. Pode-se notar essa mesma estratégia de reparo em ana, anana para se referir a banana e Rayana; ada para se referir a água e pesada. Há um "aproveitamento" de uma forma linguística já dominada na fala para se referir a uma nova, mas semelhante na pronúncia. Isso também é previsto em Modelos Baseados no Uso (BYBEE, 2001; PIERREHUMBERT, 2003), segundo os quais formas cuja representação mental é mais robusta (apresenta mais exemplares, PIERREHUMBERT, 2001) podem influenciar a produção de formas novas.

No Quadro 6, a seguir, serão analisados os dados coletados na faixa etária 1:10 a 2:0o de idade.

Quadro 6 - Dados coletados: faixa etária 1:10 a 2:00

\begin{tabular}{|c|c|c|c|c|}
\hline Sessão & Idade & Período & $\begin{array}{l}\text { Produção de } \\
\text { fala }\end{array}$ & Observações \\
\hline 53 & 1:10;02 & Outubro/2017 & $\begin{array}{c}\text { ROSA } \\
\text { ['xə.zə] } \\
{[\mathrm{z}]} \\
\text { dentalizado }\end{array}$ & $\begin{array}{c}\text { Início do segmento } / x / \\
\text { Rosa }\end{array}$ \\
\hline 54 & 1:10;03 & Outubro/2017 & $\begin{array}{l}\text { ANI ['a.ni] } \\
\text { ÓSU ['o.su] }\end{array}$ & $\begin{array}{l}\text { ANI - Josilaine (Lane) } \\
\text { ÓSU - Óculos }\end{array}$ \\
\hline 55 & $1: 10 ; 25$ & Outubro/2017 & $\begin{array}{c}\text { ANJA ['õ.zə] } \\
\text { ATETA } \\
\text { [a.'tc.tə] } \\
\text { ADA ['a.də] }\end{array}$ & Laranja, Aperta, Obrigada \\
\hline 56 & $1: 11 ; 22$ & Novembro/2017 & $\begin{array}{l}\text { AUS/AUCI } \\
\text { ['aws]/ } \\
\text { ['aw.si] }\end{array}$ & Alce (brinquedo) \\
\hline 57 & 1:11;23 & Novembro/2017 & $\begin{array}{l}\text { Sem } \\
\text { ocorrências }\end{array}$ & $\begin{array}{l}\text { Habilidade: houve desfralde e a criança } \\
\text { conseguiu usar o vaso sanitário. }\end{array}$ \\
\hline 58 & $\begin{array}{c}2 \\
\text { anos }\end{array}$ & Dezembro/2017 & $\begin{array}{l}\text { Sem } \\
\text { ocorrências }\end{array}$ & $\begin{array}{c}\text { Ainda não conseguiu abandonar a fralda, mas } \\
\text { começa a usar o vaso sanitário sozinha em } \\
\text { alguns momentos. }\end{array}$ \\
\hline
\end{tabular}

Fonte: Acervo da pesquisa

Entre 1:10 e 2:00, observou-se o início da produção do segmento /x/ (fricativa velar desvozeada) e a dentalização no segmento /s/ em ros $\rightarrow[x o z] \rightarrow$ rosa; a migração 
(metátese) do segmento /s/ para dentro da sílaba, como pode ser observado em óculos ['osu]; aférese da líquida lateral /1/ em início de palavra no exemplo Lane ['ani]. Mariana começou a produzir o segmento /3/ em sílaba final sem a produção da vogal postônica final: anja [anz]. Ocorre a duplicação de um segmento da sílaba postônica em aperta ateta [a'tztə]; a dentalização do segmento /s/ sem a produção da vogal postônica final em alce [aws]. Em 1:11 e início de 2 anos, não houve ocorrências, pois a criança estava desenvolvendo outras habilidades, como o início do desfralde.

A análise aqui empreendida quanto ao desenvolvimento fonológico individual (BYBEE, 2001, 2010; OLIVEIRA-GUIMARÃES, 2008) da criança participante mostrou que ela utiliza mais os sons alveolares $[\mathrm{t}],[\mathrm{d}],[\mathrm{n}]$ e os sons bilabiais $[\mathrm{p}],[\mathrm{b}],[\mathrm{m}]$, mas também utiliza as vogais tônicas orais $[\mathrm{a}],[\mathrm{e}],[\varepsilon],[\mathrm{i}],[\mathrm{o}],[0],[\mathrm{u}]$ e tem preferência pela nasal [ã]. Assim, quanto aos sons consonantais, nota-se uma preferência por sons mais anteriores. Além disso, como se ressaltou, a preferência por esses sons pode estar relacionada ao fato de eles ocorrerem em palavras (como “mamãe" e "papai” no caso de [m] e [p]) mais familiares para a criança e mais frequentes na língua, o que indica uma possível atuação de efeitos de frequência na aquisição (BYBEE, 2001; OLIVEIRA-GUIMARÃES, 2008).

Além disso, em suas estratégias de reparo, Mariana demonstrou preferir utilizar o tipo silábico $\mathrm{CV}$, mais frequente (BYBEE, 2001) na língua portuguesa e o tipo $\mathrm{V}$, o que também sinaliza a questão dos efeitos de frequência. Houve casos de dúvida sobre a pronúncia da criança que apontam para a aquisição gradual da fala (BYBEE, 2001), em que é possível uma produção gradiente do som (PIERREHUMBERT, 2001, 2003).

A criança apresenta várias estratégias de reparo, como a anteriorização e o apagamento de sons. Estudos como o de Lavra-Pinto (2014) apontam que estratégias de reparo como a anteriorização de consoantes velares e palatais, e o apagamento de consoante final apresentam-se com frequência na aquisição fonológica da criança com SD. Vale ressaltar que esses reparos fonológicos produzidos por Mariana, que apresenta fala atípica, podem ser apresentados em crianças de fala típica na fase inicial de aquisição da linguagem (LAMPRECHT et al., 2004). Por fim, é importante destacar que o estudo longitudinal se mostrou relevante para o acompanhamento da aquisição individual da criança avaliada, incluindo a possibilidade de se observarem regressões nessa aquisição 
(LAMPRECHT et al., 2004; BYBEE, 2010; KAIL, 2003) que não poderiam ser vistas individualmente em um estudo transversal, por exemplo.

A seguir, passam-se às considerações finais deste estudo.

\section{Considerações finais}

Abordou-se neste trabalho, por meio de um estudo de caso, o percurso de aquisição fonológica de uma criança com Síndrome de Down em uma pesquisa longitudinal, com foco nas estratégias de reparo adotadas por ela. Propôs-se observar a aquisição atípica em suas particularidades (SLOBIN, 2015). As estratégias de reparo apresentadas no presente estudo de caso estão de acordo com dados da literatura, os quais atestam que a produção da fala da criança que apresenta desvios não é aleatória, e estão de acordo com Lamprecht et al. (2004).

A criança enxerga o adulto como alvo a ser alcançado, um referencial em quem ela se espelha para desenvolver suas habilidades como andar, pegar um objeto, comer, apontar, entre outros. Essas habilidades fazem a criança perceber o modo como os adultos usam os símbolos linguísticos em diferentes situações e quanto mais ela for exposta a uma palavra, maior a chance de aprendê-la (FERRARI, 2011; BYBEE, 2001). A família, a escola, a sociedade, o acompanhamento de equipe multidisciplinar também fazem parte desse processo de desenvolvimento da criança, bem como da aquisição da fala.

A criança participante, de seus 5 meses a 2 anos de idade, apresentou a ocorrência de variados sons vocálicos e consonantais. No que se refere à produção das consoantes, Mariana mostrou ter preferência por sons mais anteriores, os alveolares [t], [d], [n] e os bilabiais [p], [b], [m]. Como se destacou, a preferência por esses sons pode estar relacionada ao fato de eles ocorrerem em palavras (como "mamãe" e "papai" no caso de [m] e [p]) mais familiares para a criança e mais frequentes na língua, o que indicaria uma possível atuação de efeitos de frequência na aquisição (BYBEE, 20o1; OLIVEIRAGUIMARÃES, 2008). Ainda, Mariana demonstrou mais facilidade para produzir o tipo 
silábico CV, mais frequente na língua portuguesa (BYBEE, 2001), o que também sinaliza para a questão dos efeitos de frequência na aquisição da fala.

A criança apresentou diversas estratégias de reparo (como a anteriorização e o apagamento sonoro, por exemplo) que são muito frequentes na fala da criança com SD (LAVRA-PINTO, 2014), mas que podem ser observadas, também, na fala de crianças com aquisição típica (LAMPRECHT et al., 2004). É importante destacar que Mariana, diante de estruturas linguísticas que ainda não domina, usou estratégias de reparo para dar conta de se comunicar, meio esse que mostra que a criança faz substituições que lhe são possíveis em termos de produção sonora e também que são possíveis dentro da língua, como podem ser observados nos dados coletados. Essas trocas se realizam com estruturas que ela já domina e que, portanto, têm representação mental mais robusta (BYBEE, 2001; PIERREHUMBERT, 2001).

Os dados deste estudo apontam para a aquisição gradual da fala (BYBEE, 2001), em que se observa uma produção gradiente de som (PIERREHUMBERT, 2001, 2003), o que pode gerar dúvidas no momento da análise auditiva dos dados.

O estudo longitudinal aqui realizado possibilitou acompanhar o desenvolvimento fonológico individual da criança, verificando-se a tendência geral de crescimento no processo de aquisição, mas também com momentos de regressão (LAMPRETCH, 2004). Como a literatura aponta, esses momentos são comuns a todas as crianças, seja de fala típica ou atípica. Neles, a criança deixa de produzir determinados segmentos ou estruturas sonoras que já produzia por um tempo, ou seja, regridem nessa aquisição, mas depois voltam a produzir as formas que tinham parado de produzir. Geralmente, esses momentos de regressão coincidem com o desenvolvimento de outras habilidades ou de aquisição de palavras novas ou estruturas mais complexas, como ocorre quando há um incremento de palavras maior no léxico ou a emergência da morfossintaxe (LAMPRECHT et al., 2004; BYBEE, 2010, KAIL, 2013). Ressalta-se que somente um estudo longitudinal permite que momentos de regressão sejam observados. Além disso, há escassez de estudos longitudinais com foco no desenvolvimento linguístico de crianças com Síndrome de Down. Dessa forma, esse tipo de estudo deve ser realizado, principalmente quando o objetivo é a observação de particularidades no desenvolvimento da fala, inclusive individuais. 


\section{Referências}

BYBEE, J. Phonology and Language Use. Cambridge: Cambridge University Press. 2001. Language, Use and Cognition. New York: Cambridge University Press, 2010.

CASTILLO-MORALES, R. Recursos ortopédicos funcionais dos maxilares: Regulação orofacial em crianças com síndrome de Down com auxílio de placa palatina. In: CASTILLO-MORALES (Org.). Terapia de regulação orofacial. São Paulo: Memmon, 1999, 181191.

CHOMSKY, N. A. Review of B. F. Skinner's Verbal Behavior. Prentice-Hall: Language, 1959.

FERRARI, L. Introdução à Linguística Cognitiva. São Paulo: Contexto, 2011.

FONSECA, J. J. S. Metodologia da pesquisa científica. Fortaleza: Apostila, 2002.

FONTES MARTINS, R. M. A organização do componente fonológico e o comportamento do indivíduo. Tese (Doutorado em Linguística) - Faculdade de Letras, Universidade Federal de Minas Gerais, Belo Horizonte, 2007.

GERHARDT, Tatiana Engel; SILVEIRA, Denise Tolfo. Métodos de Pesquisa. Porto Alegre: Editora da UFRGS, 2009.

GROllA, E.; SILVA, M. C. F. Para Conhecer Aquisição da Linguagem. São Paulo: Contexto, 2014.

OLIVEIRA-GUIMARÃES, D. M. L. Percurso de fonologia pela criança: uma abordagem dinâmica. Biblioteca Digital Da Universidade De Minas Gerais - UFMG, 2008.

KAIL, Michèle. Aquisição de Linguagem. Trad. de Marcos Marcionilo. São Paulo: Parábola, 2013.

LAMPRECHT, R. R. et al. Aquisição fonológica do português: perfil de desenvolvimento e subsídios para terapia. Porto Alegre: Artmed, 2004.

LAVRA-PINTO, Bárbara Aleixo. Consciência Fonológica e Habilidades de Escrita em Indivíduos com Síndrome de Down: um estudo longitudinal. 2014. 192 f. (Tese de 
Doutorado). Faculdade de Letras, Pontifícia Universidade Católica do Rio Grande do Sul, 2014 .

LOUSADA, M.; ALVES, D. C. e FREITAS, M. J. Avaliação linguística em contextos de desenvolvimento típico e atípico: aspetos fonéticos e fonológicos. In: FREITAS, M. J.; SANTOS, A. L. (org.). Aquisição de língua materna e não materna: Questões gerais e dados do português. Berlin: Language Science Press. 2017. p. 51-70.

MOTA, H. B. Terapia fonoaudiológica para os desvios fonológicos. Rio de Janeiro: Revinter, 2001.

OVIEDO, G. Recursos ortopédicos funcionais dos maxilares: Introdução à ortopedia funcional dos maxilares em pacientes com distúrbios neurológicos. In: CASTILLOMORALES (Org.). Terapia de regulação orofacial. São Paulo: Memmon, 1999, 173-180.

PIAGET, J. A epistemologia genética. São Paulo: Abril, 1979. (Série Os Pensadores).

PIERREHUMBERT, J. Exemplar dynamics: Word frequency, lenition and contrast. In: BYBEE, J.; HOPPER, P. (Ed.). Frequency effects and the emergence of linguistic structure. Amsterdam: John Benjamins, 2001. p. 1-19. Disponível em: $<$ www.ling.nwu.edu/ jbp/publications.html>. Acesso em 20 maio 2019.

. Phonetic diversity, statistical learning, and acquisition of phonology. Language and speech, v. 46, p. 115-154, 2003.

SANTANA, A. L. R. Placa palatina de Castillo Morales: uso precoce e qualidade de vida da criança com Síndrome de Down. Repositório Comum, 2015. Instituto Superior de Ciências da Saúde Egas Muniz - Medicina Dentária. Disponível em: https://comum.rcaap.pt/handle/10400.26/11501> . Acesso em: 19 ago. 2018.

SCARPA, E. M. A Aquisição da Linguagem. In: MUSSALIM, F.; BENTES, A. C. (Org). Introdução à linguística: Domínios e fronteiras. São Paulo: 8.ed. Cortez, 2012. p. 241-271. SCHWARTZMAN, M. L. Aspectos do desenvolvimento motor oral e da alimentação. In: SCHWARTZMAN, J. S. Síndrome de Down. 2. ed. São Paulo: Memnon: Mackenzie, 2003. SKINNER, B.F. Verbal behavior. New York: Appleton-Century-Crofts, 1957.

SLOBIN, D. I. Quebrando modelos: as línguas de sinais e a natureza da linguagem humana. Trad. Pedro Perini-Santos e Luciana Beatriz Ávila. Florianópolis: Forum Linguistic, 2015. v.12, n.3, p.844-853. Disponível em:<DI Slobin - Fórum Linguístico, 2015 - periodicos.ufsc.br>. Acesso: 23 de jul. de 2018. 
TRASK, R. L. Dicionário de Linguagem e Linguística. Tradução e adaptação de Rodolfo Ilari. São Paulo: Parábola, 2004.

VYGOTSKY, L. Thought and language. Cambridge, Harvard University Press, 1984.

YAVAS, M.; HERNANDORENA, C.; LAMPRECHT, R. Avaliação Fonológica da criança. Porto Alegre: Artmed, 2001.

Recebido em 30/o6/2019.

Aprovado em 22/12/2019. 